\title{
DENDROGRAMAS DE DENSIDADE PARA Hovenia dulcis Thunberg NA REGIÃO CENTRAL DO ESTADO DO RIO GRANDE DO SUL, BRASIL
}

\author{
DENSITY DENDROGRAM FOR Hovenia dulcis Thunberg IN THE CENTRAL REGION OF THE \\ STATE OF RIO GRANDE DO SUL, BRAZIL
}

\author{
Gerson Luiz Selle ${ }^{1}$ Frederico Dimas Fleig ${ }^{2}$ Paulo Renato Schneider ${ }^{3}$ \\ Luiz Antônio Jacques de Albernard ${ }^{4}$ Elisabete Vuaden ${ }^{5}$ Evaldo Muñoz Braz ${ }^{6}$
}

\begin{abstract}
RESUMO
O objetivo principal deste trabalho foi elaborar dendrogramas para o manejo de densidade (DMD), em populações de Hovenia dulcis localizadas na região central do estado do Rio Grande do Sul, Brasil. Para tanto, foram utilizadas informações de dois povoamentos, com idades de 25 anos, localizado na Fundação de Pesquisa Agropecuária (FEPAGRO) e de uma população de árvores livres, com DAPs variando de 5 a $45 \mathrm{~cm}$, localizado no campus da Universidade Federal de Santa Maria (UFSM), RS. Nos povoamentos sob concorrência, os dados foram coletados em árvores dos estratos dominante, intermediário e dominado, pelo método da densidade pontual. As árvores livres de concorrência foram coletadas sob a forma de censo. Como conclusão obteve-se que o modelo de Reineke ajustou-se satisfatoriamente para estimar as linhas de densidade de fechamento do dossel e de autodesbaste, com os coeficientes angulares se aproximando de $-1,5$, comprovando que a lei da potência de $-3 / 2$ de autodesbaste foi contemplada e que a hipótese postulada por Reineke tambem foi satisfeita. A densidade populacional, para a lotação do dossel, foi de $42,5 \%$ do número máximo de árvores, sendo possível construir diagramas para o manejo da densidade, dos 5 aos 31 $\mathrm{cm}$ de diâmetro da árvore de área basal média.
\end{abstract}

Palavras-chave: manejo de densidade; concorrência; linhas de densidade.

\begin{abstract}
The objective of this study was to elaborate dendrograms for the management of density, for populations of Hovenia dulcis located in the central region of Rio Grande do Sul, Brazil. To this end, we used information from 2 stands, aged 25 years, located at the Fundação de Pesquisa Agropecuária (FEPAGRO) and a population of free trees with diameters at breast height (DBH) ranging from 5 to $45 \mathrm{~cm}$, located on the campus of the Universidade Federal de Santa Maria (UFSM), RS. In stands under competition, the data were collected from trees of the dominant, intermediate, and dominated stratas by the method of density point. In trees free of competition, the data were collected in the form of census. It was found that the model Reineke adjusted satisfactorily to estimate line density of canopy closure and anthropic, with slopes approaching -1.5 , showing that the $-3 / 2$ self -thinning power law was contemplated and that the hypothesis
\end{abstract}

1. Engenheiro Florestal, Dr., Funcionário do Departamento de Ciências Florestais, Centro de Ciências Rurais, Universidade Federal de Santa Maria, Av. Roraima, 1000, CEP 97105-900, Santa Maria (RS). hs@smail.ufsm.br

2. Engenheiro Florestal, Dr., Professor Adjunto do Departamento de Ciências Florestais, Centro de Ciências Rurais, Universidade Federal de Santa Maria, Av. Roraima, 1000, CEP 97105-900, Santa Maria (RS). fdfleig@smail.ufsm.br

3. Engenheiro Florestal, Dr., Professor Titular do Departamento de Ciências Florestais, Centro de Ciências Rurais, Universidade Federal de Santa Maria, Av. Roraima, 1000, CEP 97105-900, Santa Maria (RS). paulors@smail.ufsm.br

4. Engenheiro Florestal, Profissional Autônomo Graduado pela Universidade Federal de Santa Maria, Rua Cristalino Machado Soares, 260, Casa 5, Bairro Camobi, CEP 97110-2110, Santa Maria (RS). albernardl@hotmail.com

5. Engenheira Florestal, MSc., Doutoranda pelo Programa de Pós-Graduação em Engenharia Florestal, Centro de Ciências Rurais, Universidade Federal de Santa Maria, Av. Roraima, 1000, CEP 97105-900, Santa Maria (RS). elisabetevuaden@yahoo.com.br

6. Engenheiro Florestal, Dr., Pesquisador da EMBRAPA Florestas, Estrada da Ribeira, km 111, Caixa Postal 319, CEP: 834111.000, Colombo (PR). evaldo@enpf.embrapa.br

Recebido para publicação em 29/05/2009 e aceito em 26/03/2010. 
postulated by Reineke was also satisfied. The population density for canopy capacity was $42.5 \%$ of the maximum number of trees, making it possible to construct diagrams for the management of density from 5 to $31 \mathrm{~cm}$ in diameter of average basal area of the tree.

Keywords: management of density; competition; density lines.

\section{INTRODUÇÃO}

No cenário florestal atual, o meio científico tem importante papel a desempenhar, fazendo com que as espécies atualmente plantadas tenham seu rendimento maximizado, e que sejam pesquisadas novas espécies para aumentar o restrito grupo sobre o qual se tem o domínio do processo produtivo, que vai desde o plantio até a colheita, passando pela condução dos povoamentos.

Uma das espécies que apresentam condições e características desejáveis, podendo ser cultivada, sobretudo na Região Sul do Brasil, é a uva-dojapão. Possuidora de madeira com excelentes características para o uso industrial, em móveis, pisos, paredes e armações, no meio rural, na forma de moirões, além de possuir bom poder calorífico para ser consumida como energia. Outras partes da árvore também podem ser utilizadas, como a folhagem e os frutos, na alimentação bovina e com fins apícola (SELLE et al., 1993).

A espécie ocorre naturalmente entre as coordenadas $25^{\circ}$ e $41^{\circ}$ norte e $100^{\circ}$ a $142^{\circ}$ leste, especialmente, na China, Japão e Coréias. Na América do Sul, ocorrem plantios na Argentina, Paraguai e sul do Brasil, sobretudo nas regiões de climas $\mathrm{Cfa}, \mathrm{Cfb}$ e $\mathrm{Cwa}$, de forma isolada ou em pequenos povoamentos. É uma planta heliófila, caducifólia, alcançando alturas de 10 a $15 \mathrm{~m}$, podendo chegar até a $25 \mathrm{~m}$, com copa globosa e ampla. Seu diâmetro médio à altura do peito varia entre 20 e $40 \mathrm{~cm}$ podendo chegar a $50 \mathrm{~cm}$. Seu tronco geralmente é reto e cilíndrico, apresentando fuste com até $8 \mathrm{~m}$ de comprimento, ramificação dicotômica, com ramos pubescentes enquanto jovem. Apresenta gemas dormentes subcorticais, rebrotando intensamente da touça, podendo ser manejada por talhadia, com rotações previstas de 10 a 15 anos (RIGATTO et al., 2001).

Quando se pensa na condução de povoamentos florestais, o espaçamento entre as plantas é vital, visto que é a principal técnica silvicultural aplicada em plantios florestais quando o objetivo principal é a obtenção de madeira de qualidade, com produtividade (SELLE e VUADEN, 2009). A respeito disso, Kramer e Koslowski (1960), Spiecker (1981), Schneider (1993) e Scheeren
(2003) afirmam que a concorrência ou compeição é diretamente relacionada com o espaço que cada árvore tem disponível para o seu desenvolvimento, envolvendo uma luta dinâmica pela existência em que muitos indivíduos acabam finalmente sendo eliminadas pela seleção natural. Nessa competição, sobressaem-se os indivíduos que apresentam maior atividade fisiológica, ou seja, maior tolerância à sombra. No entanto, em lugares onde fatores como a umidade do solo e o sombreamento atuam como limitadores do crescimento, o indivíduo dominante será aquele que tolera da melhor forma esses fatores.

Gomes (1997) e Berger (2002) salientam que, quanto menor a densidade de um povoamento, a madeira produzida terá uma melhor qualidade, sendo destinada para fins mais nobres como serrarias e laminação. Em contrapartida, quando o povoamento é mais denso, observam-se árvores de diâmetros menores e um grande número delas na classe dominante, produzindo madeira mais densa, destinada em especial para fins energéticos. Sanquetta (2003), em plantações de Pinus sp., constatou que em plantios com menores densidades, ocorre significativo aumento no diâmetro à altura do peito (DAP) e nas variáveis a ele correlacionado, de forma direta, concluindo que, nas densidades menores, obtem-se um menor número de fustes livres de galhos e, consequentemente, de nós. Porém, nas maiores densidades, embora as árvores sejam mais finas, o volume total é maior em razão da superfície ocupada pelas árvores. Essa mesma conclusão obteve Carvalho (2003), ao estudar Peltophorum dubium e, por Souza (2004), em pesquisa com Zeyhera tuberculosa, em que as menores médias em diâmetro estão diretamente relacionadas às maiores densidades.

Para Silva (2007), a densidade inicial geralmente é determinada antes da implantação, sendo possível que, durante o desenvolvimento do povoamento, o número de árvores varie, alterando, consequentemente, a densidade inicial. Isso foi confirmado quando o autor realizou estudos com Peltophorum dubium e concluiu que a maior sobrevivência ocorria à medida que os espaçamentos iniciais também aumentavam.

Com a evolução dos conceitos matemáticos esta competição pode ser modelada utilizando 
diferentes combinações de variáveis. Daniels et al. (1986), Durlo (1996) e Hasenauer (1997) usaram as próprias características dimensionais das árvores para a modelagem, como o diâmetro, a porcentagem e a altura da copa.

Já para Schneider (2005), entre as informações mais empregadas na relação direta com o número de árvores por hectare remanescentes estão a qualidade do sítio, o espaço vital e a idade. A respeito disso, Reineke (1933) já propunha que a relação entre o logarítmo do número de árvores por hectare e o logarítmo do diâmetro médio quadrático das árvores resultava numa linha reta, e que o declive dessa reta poderia ser usado para definir os limites do estoque máximo ou o momento em que ocorre o autodesbaste (SPURR, 1952). $\mathrm{Na}$ prática isso significa que, quando se leva a um papel logarítmo, o número de árvores no eixo das ordenadas e o diâmetro médio no das abcissas, se consegue uma relação linear entre tais variáveis. A reta resultante ajustada indica o número de árvores por hectare para um povoamento de mesma idade em densidade completa. Isso ocorre porque os indivíduos começam a morrer pela excessiva concorrência por fatores como a luz, os nutrientes e água, a qual Peet e Christensen (1987) denominaram de desbaste natural ou autodesbaste.

Uma aplicação prática dessa lei foi realizada por Lacerda e Couto (1993), com a finalidade de definir espaçamentos para Eucalyptus, obtendo como resposta que sítios de alta produtividade necessitam de espaçamentos menores. Para eles, quanto maior a disponibilidade dos fatores ligados à produtividade do local, maior poderá ser a lotação de árvores por unidade de área. No entanto, com o aumento do espaçamento médio entre as plantas, poderá ser aumentada a idade de corte, com a possibilidade de obtenção de indivíduos de maiores dimensões.

$\mathrm{Na}$ tentativa de indicar a densidade ideal, muitos índices têm sido propostos e utilizados pelos silvicultores, porém, nenhum deles é perfeito. Long e Smith (1985) denominaram os Diagramas de Manejo de Densidade (DMDs) como uma técnica baseada na teoria do autodesbaste natural dos indivíduos de um povoamento. São perceptíveis as mudanças que ocorrem com as variáveis diâmetro, altura, volume e densidade, com tais arranjos gráficos, podendo contribuir na definição da melhor densidade para a espécie de determinado povoamento, sempre levando em conta qual a finalidade da madeira produzida.
Porém, para montar os arranjos gráficos, é necessário medir o grau de concorrência em que o povoamento em estudo se encontra. Uma das formas de descrever isso é a Densidade Pontual, correlacionando o crescimento com a densidade de árvores em torno dela. O método de Spurr (1962) é um exemplo dessa técnica, que envolve a escolha de uma árvore ou ponto sobre o qual se determina o grau de concorrência em torno das árvores, teoria elaborada por Bitterlich denominada de contagem angular da amostragem.

O pionerismo na elaboração dos DMDs se deve a Ginrich (1967), porém hoje vários trabalhos já foram elaborados utilizando essa técnica, tanto para espécies coníferas como para folhosas. Exemplos de aplicações para coníferas são os trabalhos elaborados por Márquez-Linares e Alvarez-Zagoya (1995), para Pinus cooperi no México; o de Saunders e Puettmann (2000), para Picea glauca, que crescem na região norte dos EUA e, mais recentemente, o de Schneider (2008), para Pinus taeda, e o de Thomas (2009), para Pinus elliottii, ambos no Brasil. Já para folhosas, temos o de U.S. Forest Service (1970), para duas espécies de folhosas Quercus e Carya, de Illinois, EUA, o de Smith e Gibbs (1970), para Acer sacchrum em cinco regiões dos EUA, e mais recentemente o de Gezan et al. (2007) com três espécies de Nothofagus (obliqua, alpina e dombeyi) no Chile.

Segundo Ginrich (1967), o DMD de um povoamento pode ser definido por faixas de estocagem: Faixa superestocada - em que a densidade é extremamente excessiva; Faixa totalmente abastecida - em que as árvores ainda têm espaço disponível para se desenvolver, porém esse espaço é manejado para se ter o máximo de aproveitamento; Faixa subestocada - em que a densidade é baixa e o povoamento apresenta espaços disponíveis.

O mesmo autor, ao trabalhar com Quercus, cita que a linha A corresponde a $100 \%$ da lotação plena do sítio e que a linha B situa-se entre 55 e $58 \%$ dessa lotação. Também salienta que árvores dominates de Quercus "dito vermelhos do planalto" crescem perto do nível B com lotação de 63 a 42\%, já o Quercus "dito brancos do planalto" variou de 25 a 10\%, na faixa A-B. Para ele, a espécie leva, do nível de lotação $\mathrm{C}$ até o nível $\mathrm{B}$, em sítios médios, de 12 a 15 anos e, de 5 a 8 anos em sítios bons. Outra observação feita pelo pesquisador é que a capacidade de chegar na lotação completa é muito mais rápida em povoamentos jovens. 
Portanto, a correta regulagem da densidade é fundamental para uma boa condução do povoamento em conformidade com os objetivos planejados, possibilitando a predição das condições futuras do povoamento. Com a evolução dos modelos matemáticos ao longo das décadas e a incorporação dos conceitos biológicos, como a competição interespecífica, baseada em algumas das inúmeras relações de densidade e tamanho que, por sua vez, se referem às variáveis dendrométricas do povoamento, em forma de tamanho, como o número de árvores e a área basal, entre outras, tornou possível construir importantes ferramentas para a condução de povoamentos florestais. Dentre elas estão os Diagramas de Manejo da Densidade, utilizados no planejamento de intervenções silviculturais, de maneira fácil e rápida, garantindo uma ideal ocupação do sítio, mediante um controle adequado dos níveis de competição, compatibilizando com os objetivos de produção propostos.

Na presente pesquisa objetivou-se analisar e definir modelos de fechamento do dossel e de autodesbaste para populações de Hovenia dulcis com a finalidade de elaborar DMDs, bem como definir uma faixa adequada para o manejo da espécie.

\section{MATÉRIAL E MÉTODOS}

\section{Localização das áreas de estudo}

O estudo foi realizado em duas populações de Hovenia dulcis, sendo uma na Fundação Estadual de Pesquisa Agropecuária-Florestas (FEPAGRO - Figura 1-A), localizadas sob as coordenadas

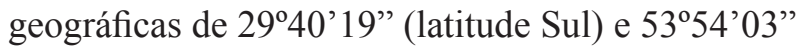

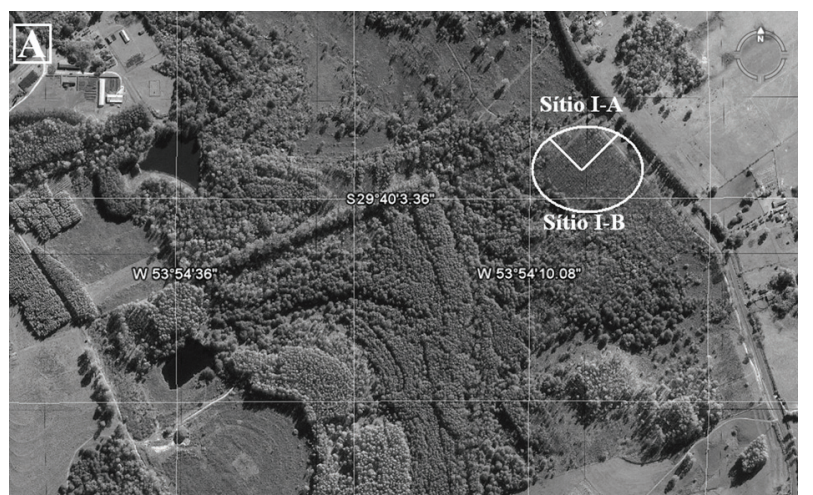

(longitude Oeste). A outra população, está situada no Campus da Universidade Federal de Santa Maria (UFSM - Figura 1-B), localizada sob as coordenadas geográficas de 29 43'33" (latitude Sul) e 53\%43'22" (longitude Oeste).

A população localizada na área da FEPAGRO foi implantada em 1983 e recebeu a denominação de Sítio I, dividido em "A" e "B". Essa divisão foi realizada porque no local ocorre variação na declividade provocando diferenciação no desenvolvimento da espécie, com o local mais elevado tendo maior desenvolvimento em altura e, o local onde o terreno é mais baixo, por causa do excesso de umidade nas camadas superficiais do solo, apresenta um menor crescimento em altura. Já a população localizada no Campus da UFSM, no Setor de Suinocultura do Departameto de Zootecnia, recebeu a denominação de Sítio II. A altitude média de ambos locais é de $120 \mathrm{~m}$, e o clima predominante, segundo a classificação de Köpen, é do tipo $\mathrm{Cfa}$, com as temperaturas médias do mês mais frio entre $13^{\circ} \mathrm{C}$ e $18^{\circ} \mathrm{C}$, e do mês mais quente superior a $22^{\circ} \mathrm{C}$, com a média anual também ficando com esse valor. A precipitação pluviométrica fica em torno dos $1.700 \mathrm{~mm}$, distribuídos regularmente durante todo o ano e, com o maior número de dias com geada ocorrendo nos meses de junho e julho (MALUF, 2000).

\section{Caracterização dos locais de coleta}

\section{Sítio I}

Esse sítio se situa sobre um Argissolo Vermelho Distrófico Típico, pertencente à unidade de mapeamento São Pedro. São solos que

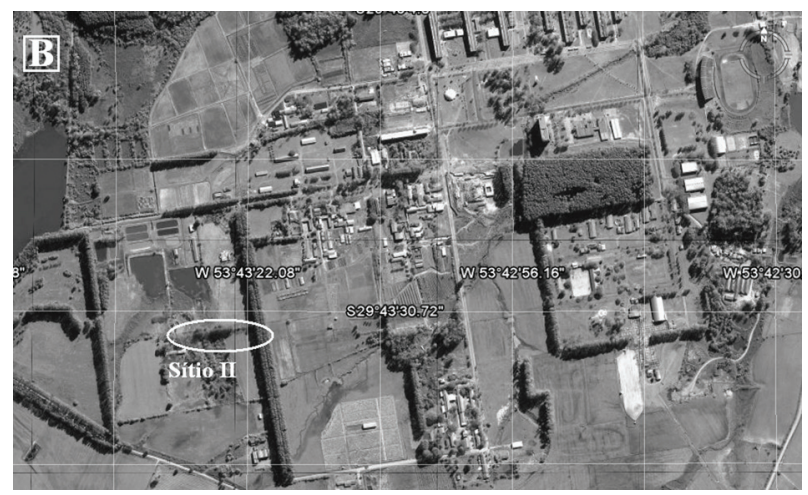

FIGURA 1: Localização das populações de Hovenia dulcis onde foram coletados os dados (Fonte: GOOGLE EARTH, 2008).

FIGURE 1: Location of the populations of Hovenia dulcis where the data were collected.

Ci. Fl., v. 20, n. 3, jul.-set., 2010 
apresentam o horizonte A espesso (em torno de $56 \mathrm{~cm}$ ), de cor bruno-escuro a bruno-avermelhado, franco argilo arenoso, com estrutura fraca em blocos subangulares e com transição clara e plana para o horizonte B (ABRÃO, GIANLUPPI e AZOLIN, 1988).

Para os mesmos autores, na análise física feita no local, foi detectado que a composição granulométrica do solo é composta de 22 a 49 e de 11 a $15 \mathrm{~g} / 100 \mathrm{~g}$ de solo, de argila e silte respectivamente, com o solo apresentando uma densidade entre 1,54 e $1,74 \mathrm{~g} / \mathrm{cm}^{3}$ e um $\mathrm{pH}$, em água, que varia de 4,7 a 5,1 . Já a análise química demonstrou proporções de fósforo $(\mathrm{P})$ e potássio $(\mathrm{K})$ disponíveis que variam entre 3,4 a 14,9 e de 22 a 76 ppm respectivamente, com um conteúdo de matéria orgânica em $\mathrm{g} / 100 \mathrm{~g}$ de solo, variando de 0,4 a 1,8 .

A população existente nesse sítio é remanescente de experimento nos quais foram testados cinco tratamentos $(4 \times 2 ; 4 \times 3 ; 4 \times 4 ; 4 \times 5$ e $4 \times 6$ m) com quatro repetições. Cada repetição composta por sete linhas de plantas distanciadas por 2 metros.

O local apresenta uma variação na declividade, refletindo no desenvolvimento da espécie, com a parte mais elevada tendo um melhor crescimento em altura. A parte mais baixa do terreno, por ter excesso de umidade nas camadas superficiais do solo, tem crescimento menor em altura.

Para este estudo, o experimento original foi considerado como uma população, sofrendo uma divisão por apresentar variação no fator sítio, identificado pela altura dominante de cada parcela. Para corrigir o problema, visando reduzir a variação interna da população, criou-se um novo arranjo para o povoamento, tendo como base a altura dominante de Assmann (1970) calculada em cada parcela. $\mathrm{Na}$ nova estrutura, os Blocos foram reclassificados em Sítios "I-A" e "I-B", conforme Tabela 1 e Figura 2.

As dimensões médias alcançadas, pela espécie no Sítio I, são de 20,5 cm, para o diâmentro e $18 \mathrm{~m}$, para a altura, aos 25 anos.

Como apresentavam poucas falhas e estas ocorreram especialmente nos menores espaçamentos, as árvores estavam submetidas a diferentes níveis de competição, com a ocorrência de sobreposição de copas.

O sub-bosque é caracterizado por uma intensa regeneração natural da espécie principal, notadamente onde os espaçamentos são maiores e a altura das árvores é menor, possibilitando a entrada de grandes quantidades de luz pelo dossel. Também pode ser verificada a presença no sob-bosque de
TABELA 1: Reestruturação do experimento, dividido em dois sítios, com base na altura dominante de Assmann de cada parcela, de Hovenia dulcis.

TABLE 1: Restructuring of the experiment, divided at two sites, based on the dominant height of Assmann of each portion of Hovenia dulcis.

\begin{tabular}{|c|c|c|c|}
\hline $\begin{array}{c}\text { Arranjo } \\
\text { original }\end{array}$ & $\begin{array}{c}\text { Arranjo } \\
\text { novo }\end{array}$ & \multirow[t]{2}{*}{$\begin{array}{l}\text { Espaçamentos } \\
\quad(\mathrm{m} \times \mathrm{m})\end{array}$} & \multirow[t]{2}{*}{$\begin{array}{l}\mathrm{h}_{100} \\
(\mathrm{~m})\end{array}$} \\
\hline & & & \\
\hline $\mathrm{B}_{1}$ & I-A & $4 \times 3$ & 22,6 \\
\hline $\mathrm{B}_{1}$ & I-A & $4 \times 6$ & 22,0 \\
\hline $\mathrm{B}_{1}$ & I-A & $4 \times 5$ & 23,2 \\
\hline $\mathrm{B}_{1}$ & I-A & $4 \times 4$ & 22,9 \\
\hline $\mathrm{B}_{1}$ & I-A & $4 \times 2$ & 20,6 \\
\hline $\mathrm{B}_{2}$ & I-A & $4 \times 5$ & 22,4 \\
\hline $\mathrm{B}_{2}$ & I-A & $4 \times 3$ & 22,7 \\
\hline $\mathrm{B}_{2}$ & I-A & $4 \times 4$ & 24,0 \\
\hline $\mathrm{B}_{2}$ & I-A & $4 \times 6$ & 22,1 \\
\hline $\mathrm{B}_{2}$ & I-B & $4 \times 2$ & 17,9 \\
\hline $\mathrm{B}_{3}$ & I-B & $4 \times 6$ & 19,7 \\
\hline $\mathrm{B}_{3}$ & I-A & $4 \times 4$ & 22,6 \\
\hline $\mathrm{B}_{3}$ & I-A & $4 \times 2$ & 23,1 \\
\hline $\mathrm{B}_{3}$ & I-B & $4 \times 5$ & 20,2 \\
\hline $\mathrm{B}_{3}$ & I-B & $4 \times 3$ & 16,6 \\
\hline $\mathrm{B}_{4}$ & I-B & $4 \times 3$ & 19,1 \\
\hline $\mathrm{B}_{4}$ & I-B & $4 \times 2$ & 18,9 \\
\hline $\mathrm{B}_{4}$ & I-B & $4 \times 4$ & 17,4 \\
\hline $\mathrm{B}_{4}$ & I-B & $4 \times 5$ & 17,3 \\
\hline $\mathrm{B}_{4}$ & I-B & $4 \times 6$ & 17,5 \\
\hline
\end{tabular}

um significativo número de outras espécies da flora nativa da região.

\section{Sítio II}

Localizado no Campus da Universidade Federal de Santa Maria, no acesso ao Setor de Suinocultura do Departamento de Zootecnica, a área é composta de exemplares de Hovenia dulcis plantados com fins de ornamentação em ambos os lados da via. No mesmo local, também foram avaliadas unidades da espécie com origem da regeneração natural, por meio da disseminação das 


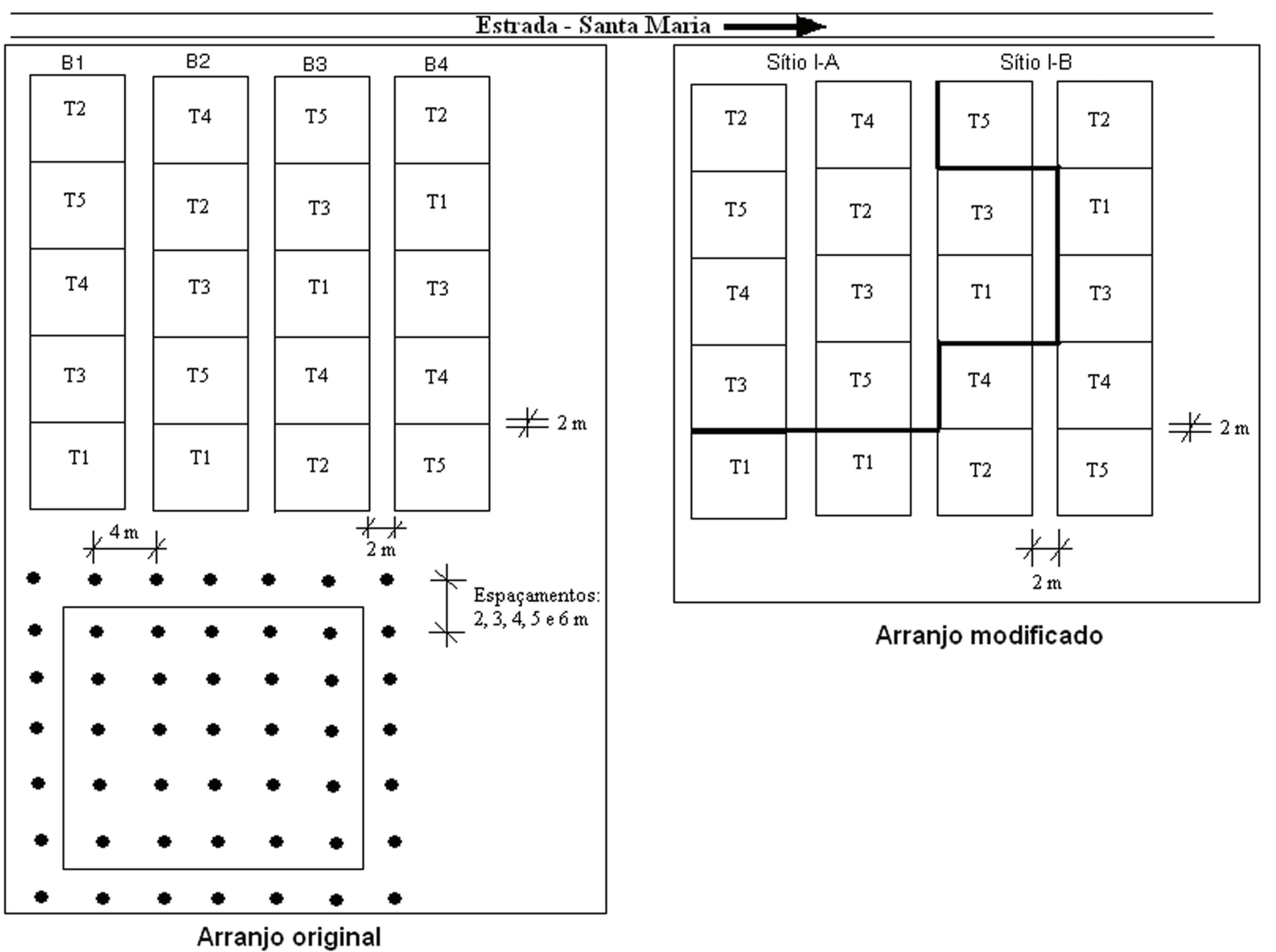

FIGURA 2: Arranjo inicial e nova ordenação da população no Sítio I, de Hovenia dulcis.

FIGURE 2: Initial arrangement and new ordination of the population in the Site I, of Hovenia dulcis.

sementes de exemplares porta-sementes existentes na área. Os diâmetros variam desde valores menores que $5 \mathrm{~cm}$ até valores superiores a $40 \mathrm{~cm}$, com as idades não sendo determinadas. O solo do local é classificado como Argissolo Vermelho-Amarelo, da formação Santa Maria, segundo Streck et al. (2008).

\section{Coleta dos dados}

\section{Árvores livres de concorrência}

Como árvores livres de concorrência, foram considerados indivíduos que compunham a população levantada no Campus da Universidade Federal de Santa Maria (Sítio II).

Foram mensurados informações como DAP, altura total, altura de inserção da copa e oito raios de copa, em indivíduos pertencentes a oito classes de diâmetro, com DAPs variando de 5 a 45 $\mathrm{cm}$, totalizando 54 árvores, conforme Tabela 2.

Os diâmetros dos fustes, medidos a 1,30 m do solo, foram mensurados com suta, em medição dupla cruzada, opostas, formando um ângulo reto entre elas, tendo-se o diâmetro médio das árvores como medida final. Já a medição das alturas das árvores foi realizada com hipsômetro Vertex e os raios das copas com um gabarito metálico descrito por Fleig (2002), sob oito raios, com o auxílio de um clinômetro para a verificação do limite da bordadura da copa e uma trena métrica para medir o comprimento do raio.

\section{Arvores sob competição}

Como árvores sob competição foram consideradas as localizadas nos Sítios I-A e I-B que ocupam uma área de 1,3 hectares.

Originalmente, cada tratamento (parcela) continha 49 árvores, separadas entre os blocos e tratamentos por uma distância de $2 \mathrm{~m}$. Cada parcela tinha uma bordadura composta de uma fileira de árvores na coluna e na linha, perfazendo 25 árvores cada.

Para a determinação do número de árvores e a área basal, utilizou-se a metodologia apresentada por Spurr (1962), denominada de Densidade Pontual, 
TABELA 2: Árvores livres de concorrência de Hovenia dulcis medidas no campus da UFSM (Sítio II).

TABLE 2: Hovenia dulcis trees free from competition measured on the campus of UFSM (Site II).

\begin{tabular}{c|c|c}
\hline $\begin{array}{c}\text { Classe de } \\
\text { diâmetro }\end{array}$ & $\begin{array}{c}\text { Centro de } \\
\text { classe }\end{array}$ & $\begin{array}{c}\text { Número de } \\
\text { Árvores }\end{array}$ \\
\hline $5,0-10,0$ & 7,5 & 6 \\
$10,1-15,0$ & 12,5 & 6 \\
$15,1-20,0$ & 17,5 & 6 \\
$20,1-25,0$ & 22,5 & 10 \\
$25,1-30,0$ & 27,5 & 7 \\
$30,1-35,0$ & 32,5 & 6 \\
$35,1-40,0$ & 37,5 & 6 \\
$40,1-45,0$ & 42,5 & 7 \\
\hline Total & - & 54 \\
\hline
\end{tabular}

muito semelhante à metodologia apresentada por Bitterlich. Todas as árvores maiores que o ângulo foram incluídas na unidade amostral, e todos os indivíduos próximos à árvore escolhida como central foram avaliadas para verificação da inclusão, ou não, na unidade amostral. Essa avaliação é baseada no FAB (fator de área basal) de 2,3, proposto por Daniels et al. (1986), para identificar árvores competidoras.

A ordem de inclusão das árvores competidoras na parcela é feita por um ranqueamento entre o diâmetro da árvore em análise e a distância desta até a árvore central. Com isso, quanto maior for essa relação, maior o ângulo criado entre a árvore central e as tangentes da árvore em análise, indicando maior influência, com esse processo sendo repetido com todas as árvores próximas à árvore central. Ao identificar que a primeira árvore participa da amostra, é encontrado um ângulo, que forma a primeira área de amostragem e com isso se faz a primeira estimativa de área basal. Prosseguindo, o segundo ângulo é encontrado para a segunda árvore e se forma a segunda área de amostragem e, partindo desta, é feita a segunda estimativa de área basal. Assim, repete-se o processo até que todas as árvores competidoras são incluídas na parcela. A estimativa final da área basal é a média das estimativas individuais.

Para a determinação da densidade pontual, foram coletadas informações de 16 árvores pontuais, em cada uma das três posições sociológicas, totalizando 48 árvores pontuais e 153 árvores vizinhas.

\section{Construção das guias de densidade}

A construção das linhas de densidade de ocupação dos locais estudados foi calculada pela relação do número de árvores, por unidade de área, em função do diâmetro de área basal média (dg), utilizado o modelo de Reineke (1933), equação 1 , que corresponde a uma relação linear entre o logarítmo do número de árvores e o logarítmo dos diâmetros $(\mathrm{dg})$.

$$
N=\alpha d^{-\beta}
$$

Em que: $\mathrm{N}$ = número de árvores por hectare; $\alpha$ e $\beta=$ parâmetros; $d=$ diâmetro de área basal média.

\section{Linha de densidade de fechamento do dossel}

A maioria dos estudos delimita essa linha baseada na de autodesbaste $(100 \%$ de ocupação do local), e fixam em um percentual aproximado de $20 \%$. No entanto, neste estudo a linha de densidade de fechamento do dossel foi obtida pelo levantamento das copas de árvores livres de concorrência, usando a metodologia proposta por Krajiceck et al. (1961).

Das árvores livres de competição foram medidos os DAPs e oito raios de copa que, pela média aritmética, forneceu os diâmetros de copa. Com base nesses diâmetros de copa, pela equação 2 , obteve-se a densidade necessária de árvores, com tal dimensão de copa e DAP, para preencher o espaço correspondente a uma unidade de área.

$$
N / h a=\frac{10000 x 4}{\pi d c^{2}}
$$
3,141593 .

Em que: $d c=$ diâmetro de copa $(\mathrm{m}) ; \pi=$

Com esses dados, ajusta-se o modelo $\mathrm{N}=f($ dap) que descreve a linha de fechamento do dossel ou linha "D".

\section{Linha de máxima densidade de ocupação}

Para a definição dessa linha, inicialmente foi calculada a área basal da população, com a equação 3 , não incluindo a árvore central da parcela, para que ocorra uma melhor relação com o crescimento da árvore central (PRODAN et al., 1997). 


$$
G=\sum^{n} \frac{d_{i}^{2}}{L_{i}^{2}}\left(i-\frac{1}{2}\right)
$$

Em que: $d=$ diâmetro medido a $1,30 \mathrm{~m}$ do solo (dap); $i=$ árvore vizinha em questão; $n=$ número recebido no ranqueamento; $L=$ distância entre a árvore central e a vizinha $i$.

De posse da área basal calculou-se o número de árvores por unidade de área com a equação 4 , descrita a seguir:

$$
N / h a=\sum_{i+1}^{n} \frac{1}{G_{i}} x F A B
$$

Em que: $G_{i}=$ área basal por hectare da unidade " $i$ "; $n=$ número recebido no ranqueamento; $F A B=$ fator de área basal $(2,3)$, proposto por Daniels et al. (1986) para identificar árvores competidoras.

A linha de máxima densidade de ocupação, ou linha "A", corresponde a uma relação teórica que descreve a trajetória seguida pelo número de árvores que se encontra em densidade máxima de ocupação, frequentemente utilizada como indicador do limite superior da capacidade máxima que o local suporta.

Para projetar a linha de máxima densidade de ocupação do local, ajustou-se o modelo de Reineke (equação 1), partindo do número de árvores por hectare em função da área basal (equação 4). Os valores ocupantes do limite superior dessa relação correspondem à linha de densidade que representa a máxima ocupação para o local, visto que, no povoamento avaliado, nos espaçamentos menores, já ocorrem mortes provocadas pela competição excessiva.

Na prática, a linha de autodesbaste ou "A" é uma projeção da linha descrita pelo modelo de Reineke que descreve a média dos pontos. Isso é realizado se incrementando o valor do intercepto " $a$ ", do modelo ajustado de Reineke elevando a linha para o limite superior, até que não ocorra mais dados acima, num diâmetro-padrão de $25 \mathrm{~cm}$.

\section{Dendrogramas de densidade e faixa de manejo}

Os DMDs foram construídos conforme metodologia proposta por Ginrich (1967), definindo-se uma faixa recomendada de manejo para o povoamento e espécie abordada.

Dependendo dos objetivos de produção é possível se obter o máximo de produtividade adensando mais ou menos a população até um limite considerado ótimo. O ideal é não trabalhar com densidade muito baixa e nem máxima, para não perder espaço em área ou fazer com que ocorram indivíduos suprimidos. Em virtude disso, é proposta uma faixa de manejo situada entre as linhas de máxima densidade e da densidade de fechamento das copas, fazendo com que as intervenções culturais efetuadas sobre o povoamento (desbastes) mantenham uma área basal e o número de indivíduos, por unidade de área, adequados de forma a ocupar o espaço eficientemente.

Conforme a metodologia de Ginrich (1967) a delimitação da faixa de manejo foi construída baseada na máxima densidade (linha de autodesbaste ou A), que corresponde a $100 \%$ de ocupação do local. Com isso, a linha superior da faixa de manejo (início da mortalidade), também conhecida como linha B, foi fixada em $57,5 \%$ e, a linha inferior da faixa, chamada de linha $\mathrm{C}$ (máxima produção), foi traçada num percentual de $42,5 \%$. Assim a zona recomendada para o manejo da espécie estudada abrange uma faixa de $15 \%$.

\section{Processamentos dos dados}

Para ajustar as regressões, foi utilizado o procedimento PROC NLIN do algoritmo de MARQUARDT.

Todos os procedimentos utilizados nos cálculos fazem parte do pacote Statistical Analysis System (SAS, 1999). Nos demais cálculos, usouse a planílha eletrônica Excel (Microsoft ${ }^{\circledR}$ Oficce, 2003).

\section{RESULTADOS E DISCUSSÃO}

\section{Guias de densidade com base na classe de copa}

\section{Linha $D$ ou de densidade de fechamento do dossel}

Também conhecida como linha de fechamento das copas, relaciona o diâmetro do fuste (DAP) e o número de árvores por hectare, determinado pelo diâmetro da copa, utilizando a equação 2. Sobre a projeção desses dados, ajustou-se o modelo de Reineke (equação 1), obtendo-se a linha de densidade de fechamento do dossel ou linha "D" cujo coeficiente angular é de aproximadamente $-1,5$ com a demonstração gráfica, em escala logarítmica, feita na Figura 3.

Árvores livres de concorrência descrevem um grau de densidade partindo do qual se dá início o 


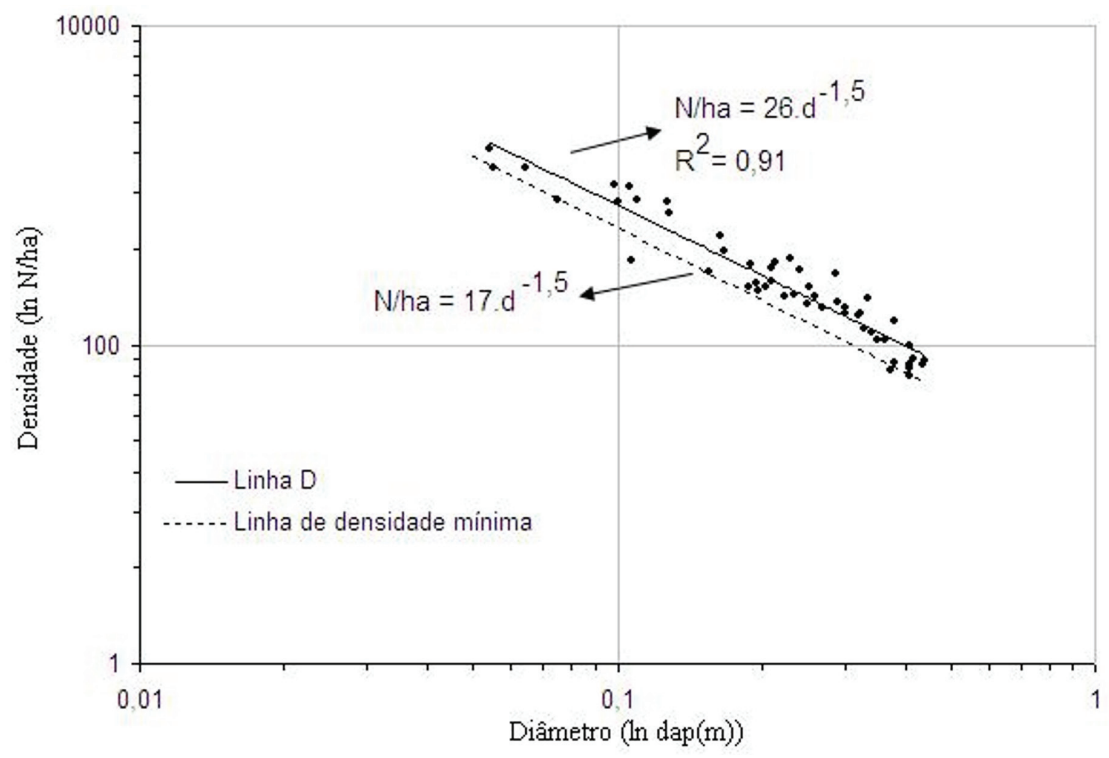

FIGURA 3: Linha de fechamento do dossel, elaboradas com árvores livres de concorrência de Hovenia dulcis, em escala logarítmica.

FIGURE 3: Line of closing of the treetops, elaborated with Hovenia dulcis trees free from competition, in logarithmic scale.

desenvolvimento de uma formação de povoamento. Abaixo desse ponto, as árvores manifestam características especiais, ou seja, em certas espécies, uma grande percentagem da altura da árvore possui galhos vivos e, consequentemente, um baixo grau de autopoda, além de apresentar copas amplas, fustes com uma altura menor em relação à de outros indivíduos da mesma espécie e idade. Por essas razões, a densidade mínima de um povoamento comercial tende a ser superior ao limitado por essa linha, fazendo com que a concorrência entre os indivíduos possa eliminar esses efeitos indesejados.

Na Figura 3, a linha denominada de mínima densidade, corresponde a um limite em que, abaixo dessa, as árvores possuem copas excessivamente grandes o que torna as árvores ineficientes por causa do grande espaço ocupado pela copa em relação ao fuste produzido.

Muito embora a linha de fechamento do dossel (linha D) tenha sido calculada neste trabalho Ginrich (1967), Archibald e Bowling (1995) e Harrington (1997) salientam que ela pode ser calculada algebricamente, sendo muito citados índices entre 15 e $25 \%$ da linha de máxima densidade (A).

Linha A, de máxima densidade ou de autodesbaste

Foi desenvolvida utilizando a metodologia da Densidade Pontual, proposta por Spurr (1962), que partindo das estimativas de área basal por hectare $(\mathrm{G})$, com a equação 3 , e número de árvores por hectare $(\mathrm{N} / \mathrm{ha})$, pela equação 4 , determinou-se o diâmetro da árvore de área basal média (dg). Tais variáveis, para as 44 unidades amostrais, constam na Tabela 3 e foram utilizadas na modelagem.

A linha de autodesbaste é a única que não pode ser obtida algebricamente e corresponde a uma relação prática que descreve a trajetória seguida pelo número de árvores de um povoamento que estejam com a máxima ocupação para o local. Nesse estágio, o povoamento está em plena competição na parte aérea, por luz, e na parte subterrânea, por água e nutrientes, fazendo com que a densidade seja dependente da mortalidade.

Sobre o número de árvores por hectare, em função do diâmetro de área basal média, de cada unidade amostral (Tabela 3), foi ajustado o modelo de Reineke (equação 1) que descreve uma linha passando pela média dos dados. Por fim, a linha que define a máxima densidade corresponde ao limite superior desses dados que, para melhor visualização, é apresentada em escala logarítmica.

Como aferição da idoneidade da equação ajustada para os pontos médios, compararam-se os dados gerados com os observados. Assim, constatouse que a função ajustada gera dados muito próximos dos observados em que, para um diâmetro de $5 \mathrm{~cm}$, a função estima uma densidade de 8.676 árvores por hectare, com área basal de $17 \mathrm{~m}^{2} / \mathrm{ha} \mathrm{e}$, para um 
Selle, G. L. et al.

TABELA 3: Área basal e número de árvores por hectare das unidades amostrais da população sob concorrência, de Hovenia dulcis.

TABLE 3: Basal area and number of trees per hectare, of the sample units of the Hovenia dulcis population under competition.

\begin{tabular}{cccc|cccc}
\hline $\begin{array}{c}\text { Unidade } \\
\text { amostral }\end{array}$ & $\mathrm{dg}(\mathrm{m})$ & $\mathrm{G}\left(\mathrm{m}^{2} / \mathrm{ha}\right)$ & $\mathrm{N} / \mathrm{ha}$ & $\begin{array}{c}\text { Unidade } \\
\text { amostral }\end{array}$ & $\mathrm{dg}(\mathrm{m})$ & $\mathrm{G}\left(\mathrm{m}^{2} / \mathrm{ha}\right)$ & $\mathrm{N} / \mathrm{ha}$ \\
\hline 1 & 0,162 & 17,65 & 855 & 23 & 0,167 & 23,45 & 1066 \\
2 & 0,142 & 9,30 & 586 & 24 & 0,107 & 16,39 & 1827 \\
3 & 0,227 & 25,35 & 625 & 25 & 0,164 & 16,83 & 798 \\
4 & 0,241 & 32,44 & 712 & 26 & 0,173 & 13,94 & 594 \\
5 & 0,164 & 8,06 & 382 & 27 & 0,119 & 13,65 & 1231 \\
6 & 0,144 & 17,28 & 1063 & 28 & 0,129 & 11,03 & 847 \\
7 & 0,100 & 9,58 & 1221 & 29 & 0,160 & 14,98 & 745 \\
8 & 0,246 & 35,81 & 754 & 30 & 0,202 & 17,87 & 557 \\
9 & 0,245 & 34,36 & 730 & 31 & 0,175 & 20,86 & 872 \\
10 & 0,182 & 8,97 & 344 & 32 & 0,182 & 16,85 & 649 \\
11 & 0,112 & 9,40 & 948 & 33 & 0,193 & 20,55 & 702 \\
12 & 0,186 & 8,56 & 314 & 34 & 0,198 & 19,38 & 628 \\
13 & 0,180 & 14,17 & 559 & 35 & 0,184 & 22,56 & 846 \\
14 & 0,263 & 32,18 & 593 & 36 & 0,178 & 15,81 & 632 \\
15 & 0,187 & 17,33 & 629 & 37 & 0,167 & 17,59 & 799 \\
16 & 0,141 & 15,58 & 1002 & 38 & 0,137 & 10,74 & 732 \\
17 & 0,227 & 38,90 & 962 & 49 & 0,240 & 29,93 & 662 \\
18 & 0,179 & 32,62 & 1297 & 40 & 0,204 & 25,19 & 768 \\
19 & 0,162 & 20,00 & 967 & 41 & 0,203 & 21,27 & 657 \\
20 & 0,150 & 15,18 & 860 & 42 & 0,161 & 11,89 & 582 \\
21 & 0,132 & 19,79 & 1437 & 43 & 0,144 & 7,28 & 448 \\
22 & 0,101 & 9,19 & 1155 & 44 & 0,154 & 18,09 & 972 \\
\hline
\end{tabular}

Em que: $d g$ = diâmetro de área basal média; $\mathrm{G}=$ área basal por hectere; $\mathrm{N} / \mathrm{ha}=$ número de árvores por hectare.

diâmetro de $31 \mathrm{~cm}$, a densidade é de 562 árvores por hectare e área basal de pouco mais de $42 \mathrm{~m}^{2} /$ ha.

$\mathrm{Na}$ prática, a linha A é definida com o incremento do valor do intercepto $(a)$ do modelo médio ajustado, elevando a linha para o limite superior, num diâmetro-padrão considerado de $25 \mathrm{~cm}$ cuja linha corresponde ao estágio de autodesbaste.

O modelo médio ajustado corresponde tão somente aos dados amostrados, podendo divergir se a amostra, do mesmo povoamento, for outra. Dessa forma, pouco muda se for fixado o coeficiente angular em $-1,5$, proposto por Tang et al. (1984), alterando o valor do intercepto até que a linha tangencie os valores extremos próximos à unidade de diâmetro de área basal média $(\mathrm{dg})$ de $25 \mathrm{~cm}$, conforme a representação gráfica da Figura 4.

$\mathrm{Na}$ literatura, é encontrada uma gama de valores para o coeficiente angular da linha de autodesbaste, mesmo fazendo uso de metodologia semelhante. Um exemplo a ser citado é o estudo de Saunders e Puettmann (2000), com cunífera que, utilizando metodologia semelhante à aplicada neste trabalho, encontraram valor de $-0,473$ para a linha de autodesbaste. Já com folhasas, Puettmann et al. (1993) definiram, como coeficiente angular da linha de máxima densidade, o valor de $-0,52$ para Pseudotsuga menziesii, e -0,64 para Alnus rubra.

Já Schneider (2008), utilizando o modelo de Tang et al. (1994) com conífera, definiu que o autodesbaste ocorre quando acontece um declínio repentino da densidade de árvores por hectare em todos os espaçamentos por ele estudado. Portanto, o autodesbaste ocorreu numa dimensão de diâmetro médio diretamente proporcional à densidade de árvores de plantio, indicando que, quanto maior o

Ci. Fl., v. 20, n. 3, jul.-set., 2010 


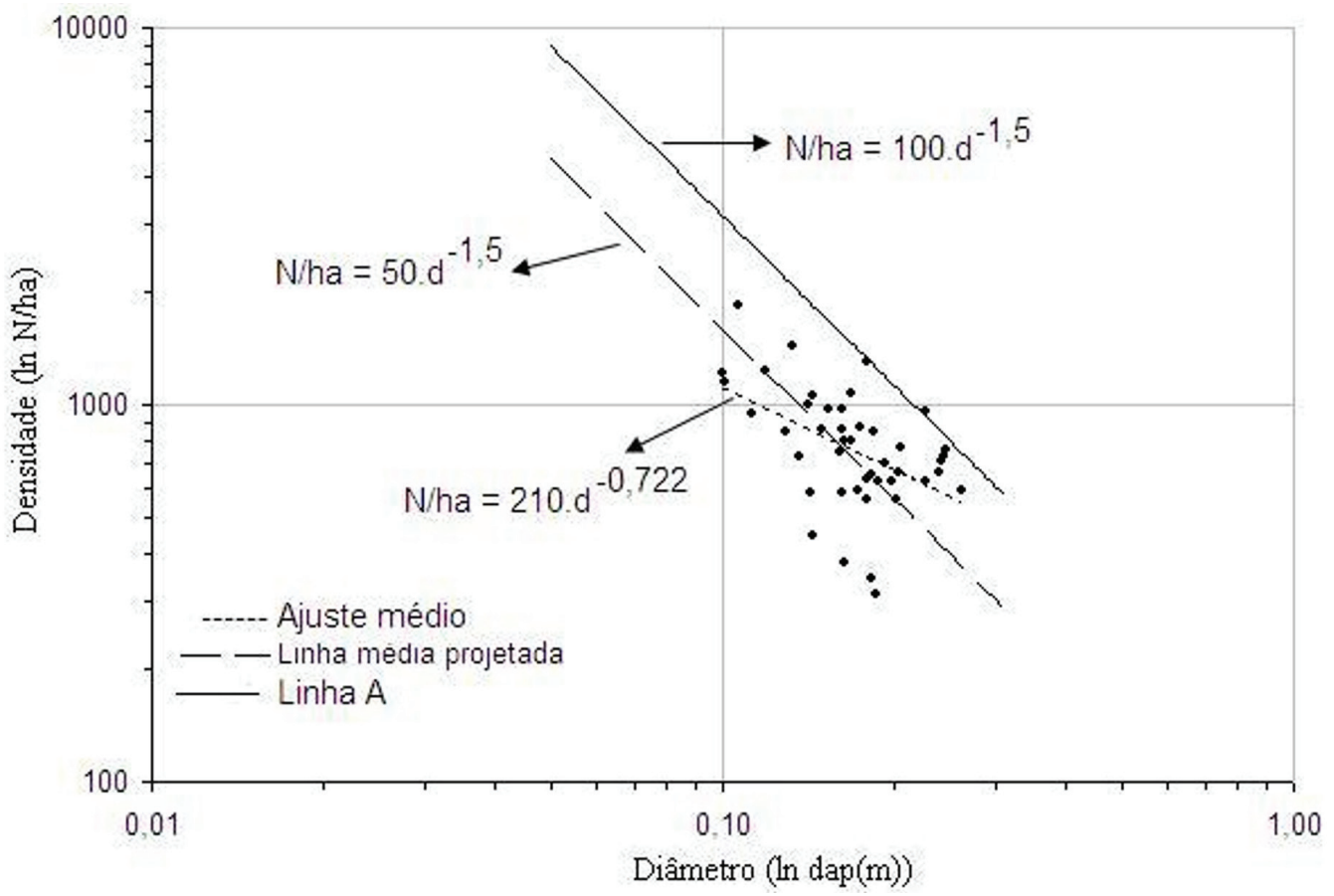

FIGURA 4: Linha de autodesbaste, para Hovenia dulcis, em escala logarítmica.

FIGURE 4: Self -thinning line, for Hovenia dulcis, in logarithmic scale.

espaçamento inicial, maior será o diâmetro médio e, com isso, mais tarde ocorrerá o momento do início do autodesbaste na população.

Muito embora os valores dos coeficientes angulares encontrados nos estudos mencionados (Puettmann et al., 1993 e Saunders e Puettmann, 2000) difiram do presente trabalho, este se aproxima mais do proposto por Yoda et al. (1963) do que o postulado por Reineke (1933).

\section{Dendrogramas de densidade e faixa de manejo}

A maioria dos pesquisadores (Ginrich, 1967, Archibald e Bowling, 1995 e Harrington, 1997) projeta as linhas de densidade algebricamente, partindo da definição da linha de autodesbaste (linha A), sem diferenciação entre coníferas e folhosas. Na literatura, as recomendações são, em relação à densidade máxima ( $100 \%$ de ocupação), as densidades teóricas de $55 \%$ para o início da mortalidade (linha B), de $45 \%$ para a máxima produção do povoamento (linha C) e de 15 a $25 \%$ para a linha que identifica o fechamento das copas (linha D).

A respeito disso, Puettmann et al. (1993) definiram a linha do início da mortalidade (B) como sendo paralela à de autodesbaste $(\mathrm{A})$ cuja densidade relativa foi de $44 \%$ para Alnu rubra, e 58\% para Pseudotsuga menziesii. Para DeBell et al. (1989), a densidade relativa, que fixa o início da mortalidade (B), é atingida quando 3\% da população perecem, isso em povoamentos de Pinus taeda, comprovado com sucessivas medições. Já a faixa de densidade ótima, indicada para operações de desbastes no manejo dos povoamentos, em que é obtido o estoque completo com ausência de autodesbaste e com bastante recuperação do volume, situou-se acima dos $30 \%$ e abaixo dos $45 \%$ da linha de autodesbaste.

No presente estudo, tanto a linha de autodesbaste (A) como a linha de fechamento do dossel (D) foram elaboradas com o ajuste do modelo Reineke (1933) para dados reais levantados em populações sob concorrência e em indivíduos livres de Hovenia dulcis respectivamente.

A linha B (50\%, menos 7,5\%, efetivamente compreendendo $42,5 \%$ da linha de autodesbaste), que neste trabalho não necessariamente reflete $o$ início da mortalidade e, sim, a linha superior de manejo, e a linha $\mathrm{C}$, linha inferior de manejo $(50 \%$, mais $7,5 \%$, efetivamente compreendendo $57,5 \%$ da linha de autodesbaste), que focaliza o início do estabelecimento da máxima produtividade do povoamento, são projetadas percentualmente em função da linha de autodesbaste (A). Assim sendo a faixa de manejo recomendada para a espécie fica em 15\%, apresentada na Figura 5, em escala logarítmica.

Além das linhas de densidade anteriormente 
Selle, G. L. et al.

apresentadas na Figura 5, usualmente são encontrados na literatura (Schneider, 2008 e Thomas, 2009) os chamados dendrogramas de estoque, propostos por Ginrich (1967), em que a densidade é definida em função da área basal e o diâmetro de área basal média (Figura 6).

Ao observar a Figura 6, nota-se a formação de três faixas entre as linhas que, segundo Ginrich

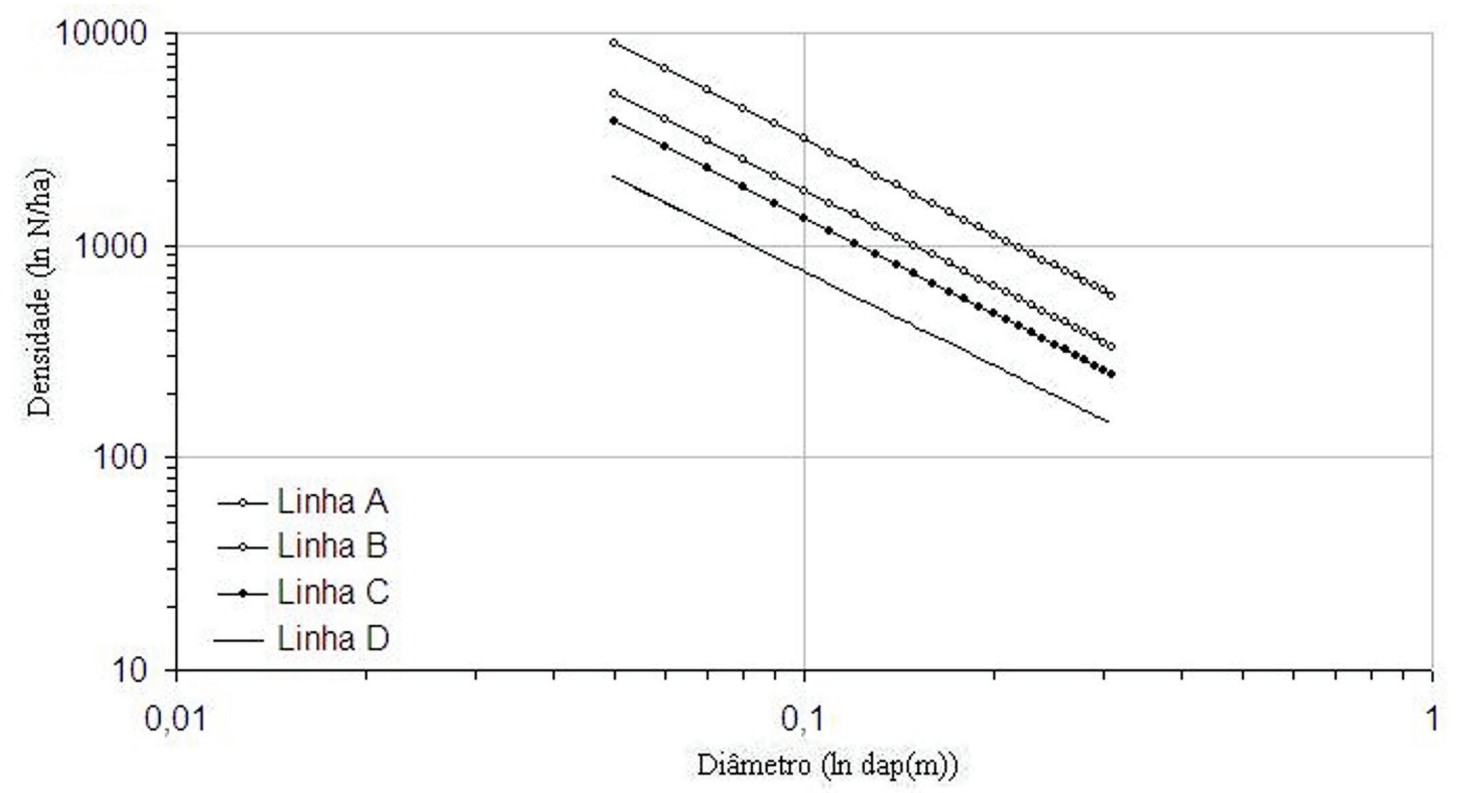

FIGURA 5: Linhas de densidade e faixa de manejo, para Hovenia dulcis, localizada na região central do estado do Rio Grande do Sul, Brasil, em escala logarítmica.

FIGURE 5: Density lines and full management, for Hovenia dulcis located in the central area of the state of Rio Grande do Sul, Brazil, in logarithmic scale.

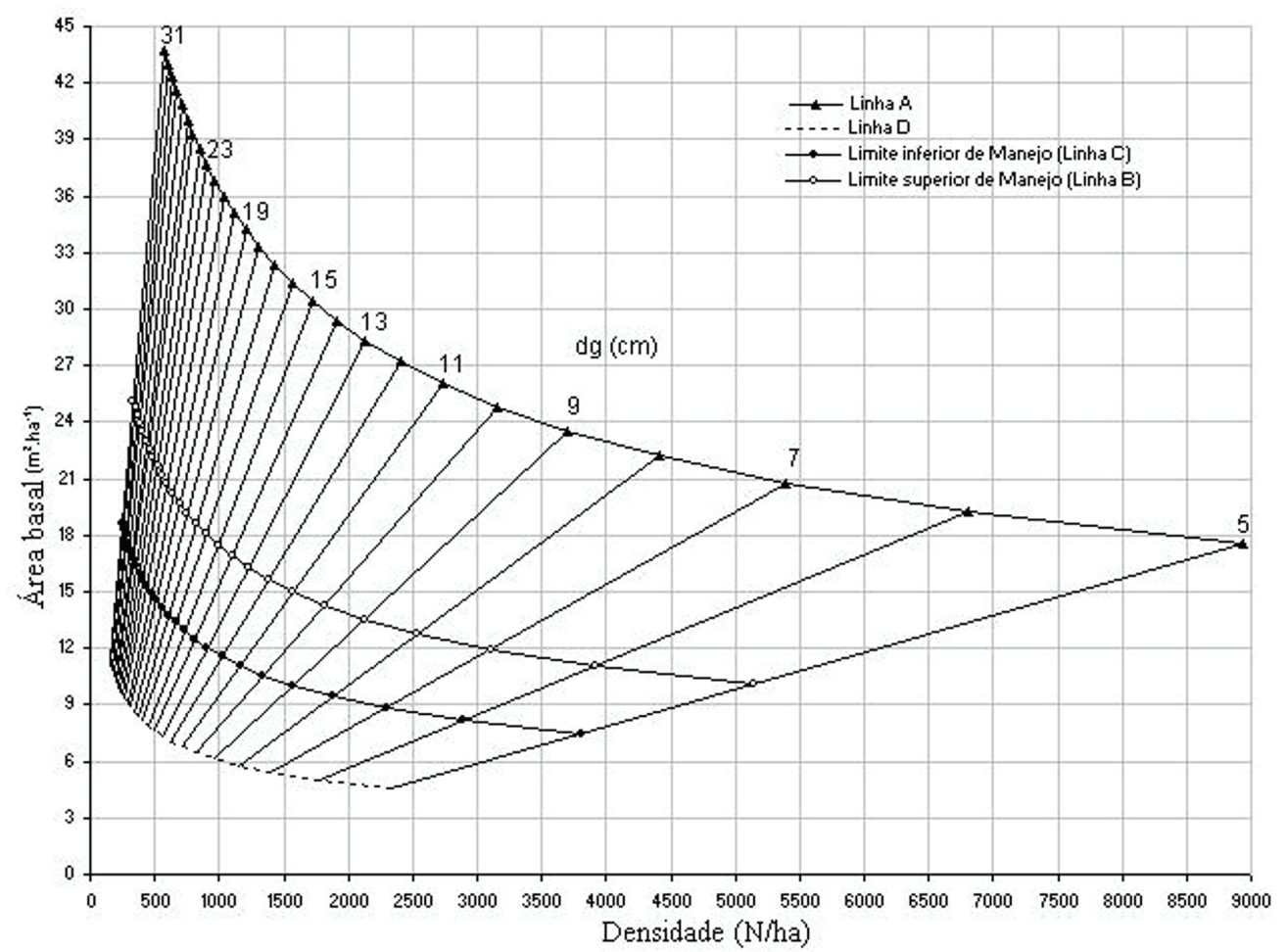

FIGURA 6: Dendrograma de densidade, para Hovenia dulcis, localizada na região central do estado do Rio Grande do Sul, Brasil.

FIGURE 6: Density Dendrogram, for Hovenia dulcis, located in the central area of the state of Rio Grande do Sul, Brazil. 
(1967), de baixo para cima, recebem a denominação de Faixa subestocada, que correspondente ao trecho entre as linhas D e C; Faixa totalmente abastecida, a que está entre as linhas B e C, também chamada de faixa recomendada de manejo e; Faixa superestocada, compreendendo o vão entre as linhas A e B.

Na Tabela 4, são apresentados valores correspondentes à linha A (autodesbaste), linha $\mathrm{B}$ (limite superior de manejo), linha C (máxima produção), e linha $\mathrm{D}$ (densidade de fechamento das copas).
Observa-se na Tabela 4 que, para a faixa recomendada de manejo da espécie, aos $25 \mathrm{~cm}$ de diâmetro de área basal média, em índices de sítios de 20 a 24 m (SELLE, 2009), com lotação de 42,5 e 57,5\%, a densidade fica entre 340 e 460 árvores/ ha, com área basal de 16,69 a $22,58 \mathrm{~m}^{2} / \mathrm{ha}^{-1}$. Já a linha de autodesbaste (A), que representa a máxima lotação para o local (100\%), no diâmetro padrão (25 $\mathrm{cm}$ ), chega a 800 árvores/ha, com uma área basal acumulada de pouco mais de $39 \mathrm{~m}^{2} / \mathrm{ha}^{-1}$.

Já para Ginrich (1967), estudando a lotação e a densidade de Quercus, nos EUA, definiu que,

TABELA 4: Densidade populacional para as linhas A, B, C e D, de Hovenia dulcis, localizada no centro de estado do Rio Grande do Sul, Brasil.

TABLE 4: Population density for the lines A, B, C and D, of Hovenia dulcis, located in the center of the state of Rio Grande do Sul, Brazil

\begin{tabular}{c|c|c|c|c|c|c|c|c}
\hline \multirow{2}{*}{$\begin{array}{c}\mathrm{dg} \\
(\mathrm{cm})\end{array}$} & \multicolumn{2}{|c|}{ Linha D } & \multicolumn{2}{c|}{ Linha C } & \multicolumn{2}{c|}{ Linha B } & \multicolumn{2}{c}{ Linha A } \\
\cline { 2 - 8 } & $\mathrm{G}\left(\mathrm{m}^{2} / \mathrm{ha}\right)$ & $\mathrm{N} / \mathrm{ha}$ & $\mathrm{G}\left(\mathrm{m}^{2} / \mathrm{ha}\right)$ & $\mathrm{N} / \mathrm{ha}$ & $\mathrm{G}\left(\mathrm{m}^{2} / \mathrm{ha}\right)$ & $\mathrm{N} / \mathrm{ha}$ & $\mathrm{G}\left(\mathrm{m}^{2} / \mathrm{ha}\right)$ & $\mathrm{N} / \mathrm{ha}$ \\
\hline 5 & 4,57 & 2326 & 7,46 & 3801 & 10,10 & 5143 & 17,56 & 8944 \\
6 & 5,00 & 1769 & 8,18 & 2892 & 11,06 & 3912 & 19,24 & 6804 \\
7 & 5,40 & 1404 & 8,83 & 2295 & 11,95 & 3105 & 20,78 & 5399 \\
8 & 5,78 & 1149 & 9,44 & 1878 & 12,77 & 2541 & 22,21 & 4419 \\
9 & 6,13 & 963 & 10,01 & 1574 & 13,55 & 2130 & 23,56 & 3704 \\
10 & 6,46 & 822 & 10,56 & 1344 & 14,28 & 1818 & 24,84 & 3162 \\
11 & 6,77 & 713 & 11,07 & 1165 & 14,98 & 1576 & 26,05 & 2741 \\
12 & 7,07 & 625 & 11,56 & 1022 & 15,64 & 1383 & 27,21 & 2406 \\
13 & 7,36 & 555 & 12,04 & 907 & 16,28 & 1227 & 28,32 & 2133 \\
14 & 7,64 & 496 & 12,49 & 811 & 16,90 & 1098 & 29,39 & 1909 \\
15 & 7,91 & 448 & 12,93 & 732 & 17,49 & 990 & 30,42 & 1721 \\
16 & 8,17 & 406 & 13,35 & 664 & 18,06 & 898 & 31,42 & 1563 \\
17 & 8,42 & 371 & 13,76 & 606 & 18,62 & 820 & 32,38 & 1427 \\
18 & 8,66 & 340 & 14,16 & 557 & 19,16 & 753 & 33,32 & 1309 \\
19 & 8,90 & 314 & 14,55 & 513 & 19,69 & 694 & 34,23 & 1207 \\
20 & 9,13 & 291 & 14,93 & 475 & 20,20 & 643 & 35,12 & 1118 \\
21 & 9,36 & 270 & 15,30 & 442 & 20,70 & 598 & 35,99 & 1039 \\
22 & 9,58 & 252 & 15,66 & 412 & 21,18 & 557 & 36,84 & 969 \\
23 & 9,79 & 236 & 16,01 & 385 & 21,66 & 521 & 37,67 & 907 \\
24 & 10,00 & 221 & 16,35 & 361 & 22,12 & 489 & 38,48 & 851 \\
25 & 10,21 & 208 & 16,69 & 340 & 22,58 & 460 & 39,27 & 800 \\
26 & 10,41 & 196 & 17,02 & 321 & 23,03 & 434 & 40,05 & 754 \\
27 & 10,61 & 185 & 17,34 & 303 & 23,47 & 410 & 40,81 & 713 \\
28 & 10,81 & 175 & 17,66 & 287 & 23,90 & 388 & 41,56 & 675 \\
29 & 11,00 & 166 & 17,98 & 272 & 24,32 & 368 & 42,30 & 640 \\
30 & 11,18 & 158 & 18,28 & 259 & 24,74 & 350 & 43,02 & 609 \\
31 & 11,37 & 151 & 18,58 & 246 & 25,14 & 333 & 43,73 & 579 \\
\hline
\end{tabular}

Em que: $\mathrm{dg}=$ diâmetro de área basal média; $\mathrm{N} / \mathrm{ha}=$ número de árvores por hectere; $\mathrm{G}=$ área basal por hectare. 
para uma densidade de 81 árvores/ha, com uma área basal de $20,7 \mathrm{~m}^{2} /$ ha, obteve uma lotação de $80 \%$ do sítio, em um povoamento com 22,9 cm de diâmetro médio. Para ele, a linha $\mathrm{C}$ variou de 55 a $58 \%$ da lotação máxima do sítio. Também cita que a espécie leva em torno de 10 anos para passar da linha $\mathrm{C}$ para a $\mathrm{B}$, em povoamentos situados entre os índices de sítios 16,76 e $22,86 \mathrm{~m}$ (55 e 75 pés). O autor ainda acrescenta que o intervalo de tempo entre as linhas $\mathrm{D}$ e C poderia levar de 12 a 15 anos para ser atingido pelos povoamentos localizados em sítios médios e, de 5 a 8 anos, para os localizados em sítios bons.

\section{CONCLUSÕES}

De acordo com os resultados obtidos no presente estudo, concluiu-se que:

O modelo de Reineke ajustou-se com boa precisão, estimando as linhas de fechamento do dossel (D) e de autodesbaste (A), com coeficiente angular de aproximadamente -1,5, o que contempla a lei da potência de autodesbaste formulada por Yoda et al. e se aproxima muito da hipótese postulada por Reineke;

A densidade populacional, para o início da total lotação do dossel é de $42,5 \%$ do número máximo de árvores que o local permite;

Com os dados coletados, foi possível construir diagramas para o manejo da densidade, dos 5 aos $31 \mathrm{~cm}$ de diâmetro da árvore de área basal média;

A faixa estimada como adequada de manejo da espécie, para um diâmetro de área basal média de $25 \mathrm{~cm}$, com lotação entre 42,5\% e 57,5\%, a densidade fica entre 340 e 460 árvores/ha, com área basal de 16,69 a $22,58 \mathrm{~m}^{2} / \mathrm{ha}^{-1}$.

\section{REFERÊNCIAS BIBLIOGRÁFICAS}

ABRÃO, P. U. R.; GIANLUPPI, D.; AZOLIN, M. A. D. Levantamento semidetalhado dos solos da Estação Experimental de Silvicultura de Santa Maria. Porto Alegre, 1988. 75 p.

ARCHIBALD, D. J.; BOWLING, C. Jack pine density management diagram for boreal Ontario: Northeast Science \& Technology. NEST Technical Note TN-05. 1995, 19 p.

ASSMANN, E. The principles of forest yield study. New York: Pergamon Press, 1970. 506 p. BERGER, R. Efeito do espaçamento e da adubação no crescimento de um clone de Eucalyptus saligna Smith. Ciência Florestal, Santa Maria, v. 2, n. 2, p.
75-87, jan./dez. 2002.

CARVALHO, P. E. R. Espécies arbóreas brasileiras. Brasília: Embrapa Informação Tecnológica; Colombo: Embrapa Florestas, 2003. 1 v. 1039 p. (Coleção Espécies Arbóreas Brasileiras). DANIELS, R. F.; BURKHART, H. E.; CLASON, T. R. A comparison of competition measures for predicting growth of loblolly pine trees. Canadian Journal for Forest Research, Montreal, v. 16, n. 6, p. 1230-1237, Dec. 1986.

DeBELL, D. S.; HARMS, W. R.; WHITESELL, C. D. Stockability: a major factor in productivity differences between Pinus taeda in Hawaii and the southeastern United States. Forest Science, Bethesda, v. 35, n. 3, p. 708-719, Sept. 1989.

DURLO, M. A. Zuwachsuntersuchungen und Einzelbaumwachtumodelle für Cabralea glaberrima, Cedrela fissilis und Cordia trichotoma in sekundären Laubmischwäldern Südbrasiliens. 1996. 175 f. Dissertation (Doktorat) - Universität fur Bodenkultur, Seiten, Wien, 1996.

FLEIG, F. D. Morfometria e Quantificação da Biomassa Comercial e Residual da poda de erva-mate (Ilex paraguariensis St. Hil.) em reflorestamentos. 2002. 140 f. Tese (Doutorado em Engenharia Florestal) - Universidade Federal de Santa Maria, Santa Maria, 2002.

GEZAN, S. A.; ORTEGA, A.; ANDENMATTEN, E. Diagramas de manejo de densidad para renovales de roble, raulí y coigüe em Chile. Bosque, Valdivia, v. 28, n. 2, p. 97-105, jul./dic. 2007.

GINRICH, S. R. Measuring and evaluating stocking and stand density in upland hardwood forests in the central states. Forest Science, Bethesda, v. 13, n. 1, p. 28-53, Feb. 1967.

GOMES, F. S. Avaliação da produção em volume total e sortimento em povoamentos de Pinus taeda submetidos a diferentes condições de espaçamento inicial e sítio. Ciência Florestal, Santa Maria, v. 7, n. 1, p. 101-126. jan./dez, 1997.

GOOGLE EARTH. Software licensidado pela Google. v. 5.0, EUA, 2008.

HARRINGTON, T. B. Silvicultural approaches for thinning southern pines: method, intensity and timing. School of Forest Resources, Geórgia, EUA, Disponível em: <www.gfc.state.ga.us/ Resources/Publications/ForestManagement/ SilviculturalApproaches.pdf $>$. Acesso em 5 set. 2008. 17 p. 1997.

KARAJICECK, J.; BRINKMAN, K.; GINGRICH, S. R. Crown-competition: a measure of density. Forest Science, Bethesda, v. 7, n. 1, p. 35-42, Feb. 
1961.

KRAMER, P. J., KOSLOWSKI, T. T. Fisiologia das árvores. Lisboa: Fundação Calouste Gulbenkian, 1960. $745 \mathrm{p}$.

LACERDA, J. S.; COUTO, H. T. Z. O uso da lei do autodesbaste na definição do espaçamento para plantios de Eucalyptus. Circular Técnica IPEF, Piracicaba, n. 182, abr. 1993.

LONG, J. N.; SMITH, F. W. Relation between size and density in developing stands - a description and possible mechanisms. Forest Ecology and Management, St. Louis, v. 7, n. 2, p. 191-206, Feb. 1985.

MALUF, J. R. T., Nova classificação climática do estado do Rio Grande do Sul. Revista Brasileira de Agrometeorologia, Santa Maria, v. 8, n. 1, p. 141150, jan. 2000.

MÁRQUEZ-LINARES, M. A.; ALVAREZZAGOYA, R. Construcción de uma guía de densidad para Pinus cooperi var. ornelasi com base en la clase de copa em Durango, México. Madera y Bosques, México, v. 1, n. 2, p. 23-36, May./Sept. 1995.

MICROSOFT@ OFICCE EXCEL. Parte do produto Microsoft Office Professional 2003. Copyright ${ }^{\circledR} \quad$ 1985-2003 Microsoft Corporation. 2003.

PEET, R. K.; CRISTENSEN, N. L. Composition and tree death. BioScience, Washington, v. 37, n. 11, p. 586-681, Nov. 1987.

PRODAN, M. et al. Mensura Forestal. San José: IICA, 1997. 586 p. (Serie Investigación y Educación en Desarrollo Sostenible).

PUETTMANN, K. J.; HANN, D. W.; HIBBS, D. E. Evaluation of the size-density relationships for pure red alder and Douglas-Fir stands. Forest Science, Bethesda, v. 39, n. 1, p. 7-27, Feb. 1993.

REINEKE, L. H. Perfecting a stand-density-index for even aged forests. Journal of Agricultural Research, Beltsville, v. 7, n. 46, p. 627-638, Jan./ Dec. 1933.

RIGATTO, P. A. et al. Características físicas, químicas e anatômicas da madeira de Hovenia dulcis. Colombo: EMBRAPA Florestas, 2001. 4 p. (Comunicado Técnico).

SANQUETTA, C. R. Produção de madeira livre de nós em povoamentos de Pinus taeda em função da densidade de plantio. Cerne, Lavras, v. 9, n. 2, p.129-140, jul./dez. 2003.

SAS. The SAS System for Windows. Copyright (c) 1999-2001 by SAS Institute Inc., Cary, NC, USA. 1999.
SAUNDERS, M. R.; PUETTMANN, K, J. A preliminary white spruce density management diagram for the lake states. Minnesota: Department of Forest Resources. College of Natural Resources and Minnesota Agricultural Experiment Station. University of Minnesota. 2000. 14 p. (Sraff Paper Series, n. 145).

SCHEEREN, L. W. Estruturação da produção de provoamentos monoclonais de Eucalyptus saligna Smith manejados em alto fuste. 2003. $181 \mathrm{f}$. Tese (Doutorado em Engenharia Florestal) Universidade Federal de Santa Maria, Santa Maria, 2003.

SCHNEIDER, P. R. Análise da mortalidade de Acácia mearsi de Wild. Ciência Florestal, Santa Maria, v. 15, n. 2, p.137-143, abr./jun. 2005.

SCHNEIDER, P. R. Introdução ao manejo florestal. Santa Maria: CEPEF/FATEC, 1993. 348 p.

SCHNEIDER, P. S. P. Autodesbaste e diagrama de manejo da densidade em povoamentos de Pinus taeda L. 2008. 94 f. Dissertação (Mestrado em Enganharia Florestal) - Universidade Federal de Santa Maria, Santa Maria, 2008.

SELLE, G. L. et al. Influência de diferentes tipos de cobertura na germinação e sobrevivência de mudas de uva-do-japão. Agropecuária Catarinense, Florianópolis, v. 6, n. 4, p. 20-22, nov. 1993.

SELLE, G. L. Guias de densidade e índices de sítios para Hovenia dulcis Thunberg na região central do estado do Rio Grande do Sul, Brasil. 2009. 97 f. Tese (Doutorado em Engenharia Florestal) - Univesidade Federal de Santa Maria, Santa Maria, 2009.

SELLE, G. L.; VUADEN, E. Comportamento do mercado de produção e do consumo de madeira serrada. Caderno de Pesquisa: Série Biologia, Santa Cruz do Sul. 2009. (prelo).

SILVA, L. T. M. Morfometria, qualidade do tronco e da copa de Peltophorum dubium (Spreng.) Taub. em povoamento experimental no estado do Rio Grande do Sul. 2007. 76 f. Dissertação (Mestrado em Engenharia Florestal) - Universidade Federal de Santa Maria, Santa Maria, 2007.

SMITH, C.; GIBBS, C. B. A guide to sugarbusch stocking: based on the crown diameter/D.b.h. relationship of open-grown sugar maples. Washington: Forest Service, 1970. 10 p. (Reserarch Paper NE-171).

SOUZA, C. C. Modelo de crescimento, com variáveis ambientais, para o ipê- felpudo em diferentes espaçamentos. 2004. 96 f. Dissertação 
(Mestrado em Engenharia Florestal) - Escola Superior de Agricultura "Luiz de Queiroz", Piracicaba, 2004.

SPIECKER, H. Análise do crescimento florestal: a concorrência e sua importância no desbaste. Curitiba: FUPEF, 1981. 62 p. (Série Técnica FUPEF).

SPURR, S. H. A measure of point density. Forest Science, Bethesda, v. 8, n. 1, p. 85-96, Feb. 1962. SPURR, S. H. Forest Inventory. New York: The Ronald Press Company, 1952. 476 p.

STRECK, E. V. et al. Solos do Rio Grande do Sul. Porto Alegre: Emater/RS, UFRGS, 2008. 222 p.

TANG, S. et al. A growth and self-thinning model for purê even-aged stands: theory and applications.

Forest Ecology and Management. St. Louis, v. 70, n. 1, p. 67-73, Jan. 1984.

THOMAS, C. Dendrograma de manejo de densidade para povoamentos de Pinus elliottii Engelm na região central do Rio Grande do Sul. 2009. 60 f. Dissertação (Mestrado em Engenharia Floresal) - Universidade Federal de Santa Maria, 2009.

U.S. FOREST SERVICE. Relation of crown width to tree diameter in same upland hardwood stands of southern Illinois. St. Paul: Southern Forest Experiment Station Library. 1970. 4 p. (Research Note nc-99).

WEST, P. W.; BOUROUGH, C. J. Tree supervision and the self-thinning. Rule in a monoculture of Pinus radiata D. Don. Annals of Botany, London, v. 52, n. 2, p. 149-158, July/Dec. 1983.

YODA, K. et al. Self-thinning in over rowed pur stands under cultivated and natural conditions. Journal Biology, London, v. 14, n.1., p. 107-129, Jan./Dec. 1963.

Ci. Fl., v. 20, n. 3, jul.-set., 2010 